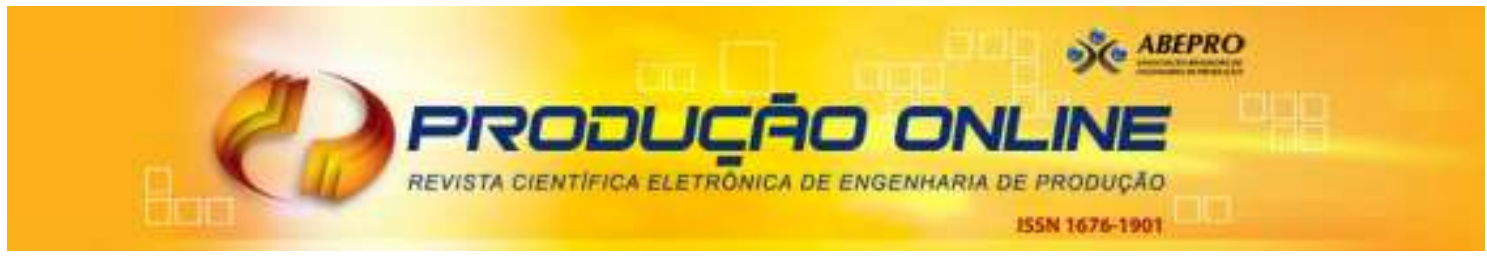

\title{
AVALIAÇÃO DO DESEMPENHO AMBIENTAL DE UMA EMPRESA DE TRATAMENTO SUPERFICIAL DE ALUMÍNIO
}

\section{ENVIRONMENTAL PERFORMANCE ASSESSMENT OF A COMPANY OF ALUMINUM SURFACE TREATMENT}

\author{
Susan Catieri Ramalho*E-mail: susanramalho@hotmail.com \\ Miguel Afonso Sellitto* E-mail: sellitto@unisinos.br \\ *Universidade do Vale do Rio dos Sinos (UNISINOS), São Leopoldo, RS.
}

\begin{abstract}
Resumo: O objetivo deste artigo foi avaliar o desempenho ambiental de uma empresa de tamanho médio que presta serviços de tratamento superficial de alumínio. O tratamento é conhecido como anodização. $\mathrm{O}$ método de pesquisa foi a modelagem numérica qualitativa. $\mathrm{O}$ desempenho ambiental da empresa foi organizado em cinco construtos: atmosfera, efluentes, recursos naturais e energéticos, resíduos sólidos, e legislação e gestão. Dezenove indicadores foram escolhidos para explicar os cinco construtos. Dez colaboradores da empresa priorizaram os construtos e avaliaram a situação dos indicadores por meio de uma escala de avaliação. Por meio de modelo matemático, o desempenho geral ambiental da operação foi calculado em $74,5 \%$ do máximo possível. Os indicadores que mais contribuíram para que o desempenho não fosse de $100 \%$ foram consumo de energia elétrica e consumo de água. $\mathrm{O}$ construto de pior desempenho foi Recursos Naturais e Energéticos. Estas são as prioridades para futuras ações de melhoria ambiental que a empresa venha a promover.
\end{abstract}

Palavras chave: Desempenho Ambiental. Gestão Ambiental. Impactos Ambientais.

Abstracts: The purpose of this article was to evaluate the environmental performance of a mediumsized company that provides services for surface treatment of aluminum. The treatment is known as anodizing. The research method was qualitative numerical modeling. The environmental performance of the company was organized into five constructs: atmosphere, wastewater, energy and natural resources, solid waste, and legislation and management. Nineteen indicators were chosen to explain the five constructs. Ten employees of the company prioritized the constructs and evaluated the situation of the indicators by means of a scale of assessment. By means of a mathematical model, the general performance of the environmental operation was calculated at $74.5 \%$ of the maximum possible. The indicators that most contributed to the performance not to reach $100 \%$ were consumption of electricity and water consumption. The construct of worse performance was natural and energy resources. These are the priorities for future environmental improvement actions that the company may promote.

Keywords: Environmental performance. Environmental Management. Environmental Impacts.

\section{INTRODUÇÃO}

As discussões e ações voltadas para a temática do meio ambiente e de sua conservação têm aumentado nos últimos anos, principalmente em relação aos 
impactos gerados por atividades industriais. O setor industrial tem sido pressionado por ações governamentais e pela sociedade em geral, para que promova rápida e eficiente adequação frente a questões que têm sido colocadas, tais como: redução da poluição, mais eficiência no uso de recursos energéticos e naturais, melhor gerenciamento de processos e lançamento de produtos mais amigáveis ambientalmente (SELLITTO et al., 2012). Dentre as exigências da sociedade com relação às atividades industriais, a preocupação com o meio ambiente ganha destaque em função de sua relevância para qualidade de vida das populações, e isto exige das empresas um novo posicionamento em sua interação com o meio ambiente (DONAIRE, 2010).

A capacidade humana de modificar o meio ambiente aumentou após a Revolução Industrial. Nos primeiros tempos de atividade industrial, esta capacidade foi saudada positivamente, pois a disponibilidade de novas e abundantes fontes de matérias-primas extraídas da natureza trouxe expressivo avanço econômico. $\mathrm{O}$ mesmo se deu em relação a fontes energéticas (BORCHARDT et al., 2008). Mais tarde, no entanto, principalmente a partir dos anos 1960, surgiu uma visão mais pessimista em relação à exploração da natureza com fins econômicos. A partir da segunda metade do século $X X$, observou-se que a geração de resíduos industriais cresceu em ritmo superior à capacidade que a natureza possui de absorvê-los. Também cresceu a geração de resíduos de difícil degradação por meios naturais e de resíduos de maior potencial de risco e de toxicidade (RIBEIRO e MORELLI, 2009).

Evidenciou-se a partir de então a existência de uma relação de interdependência entre $\mathrm{o}$ crescimento da economia e o risco ambiental. Adicionalmente, constatou-se a existência de limites ambientais impostos ao crescimento econômico. Foi necessário desenvolver políticas e legislações para que se conseguisse conciliar e harmonizar a atividade econômica com a proteção do meio ambiente (SEIFFERT, 2011). Crescimento econômico e conservação ambiental já não são considerados contraditórios: para alcançar um não necessariamente deve-se abrir mão do outro (ARAUJO; MACHADO, 2007). Algumas destas políticas têm se materializado sob a forma de legislações, tratados, acordos e convenções 
nacionais ou internacionais discutidas em cimeiras que tiveram ampla repercussão social e nos meios de comunicação (DINIZ; OLIVEIRA, 2009).

Um dos meios pelos quais as empresas podem tentar equilibrar as necessidades de desempenho econômico e de conservação ambiental é pelo desenvolvimento de sistemas de gestão ambiental (SGA). A implantação e o uso de SGA's têm ajudado empresas industriais a melhorarem seu desempenho em responsabilidade social e ambiental, sem abrir mão do desempenho econômico de seus produtos e serviços (WALKER et al., 2008). SGA's permitem a estruturação de métodos de medição e de avaliação de desempenho, mesmo que não existam nas normas requisitos específicos para tal. Zobel et al. (2002) definiram desempenho ambiental como a informação analítica oferecida por múltiplos indicadores organizados sob a forma de um sistema de mensuração. Empresas industriais que adotaram um tipo de método de avaliação que forneça mensuração contínua do desempenho ambiental têm encontrado mais facilidade para estipular e direcionar ações de correções segundo metas e objetivos ambientais (JURY et al., 2013). Métodos de avaliação de desempenho ambiental podem ajudar na priorização de objetivos e em ações de correção ambiental e podem, portanto, melhorar os resultados da gestão ambiental de empresas industriais (KUHRE, 1998).

O objetivo geral deste artigo foi avaliar o desempenho ambiental de uma empresa industrial que presta serviços de tratamento superficial de alumínio. A empresa é do tipo PME (pequena e média empresa). Os objetivos específicos do artigo foram: definir os construtos latentes e seus respectivos indicadores; mensurálos; e usar a mensuração para discussão e priorização de ações ambientais. O método de pesquisa foi a modelagem numérica qualitativa. $\mathrm{O}$ modelo matemático se originou de opiniões e impressões de especialistas, organizadas em formato numérico.

Indicadores ambientais podem ser divididos em: impacto direto no ambiente; atendimento a legislações; e eficiência em processos gerenciais de controle (DELMAS; BLASS, 2010). Também podem ser divididos em: regulatórios; sanitários e ambientais; e econômicos (ASKHAM et al., 2012). Para este artigo, interessam indicadores ambientais e regulatórios. $O$ artigo segue linha de pesquisa com alguns resultados já publicados. Dentre estes resultados, citam-se Antonov e Sellitto (2011), 
Sellitto et al. (2010) e Sellitto et al. (2012). Especificamente em PME, alguns resultados foram publicados em Sellitto et al. (2009b). Uma delimitação da linha que foi mantida neste artigo é que a mesma estuda exclusivamente empresas cujas atividades principais sejam do tipo industrial. Empresas que sejam exclusivamente prestadoras de serviços, por ora, não são objetivo de pesquisa.

O restante do artigo está organizado em: revisão bibliográfica, método de pesquisa, resultados de pesquisa, e considerações finais. A pesquisa foi totalmente financiada pelo CNPq.

\section{REVISÃO BIBLIOGRÁFICA}

Um dos fatores que mais chamaram a atenção da opinião pública e que mais contribuíram para confirmar a importância do tema e para conscientização sobre riscos ambientais foram os inúmeros acidentes ocorridos nos últimos 50 anos (DIAS, 2011). O autor aponta que desastres ambientais envolvendo grandes empresas e atividades industriais e de transporte, amplamente divulgados e discutidos nos meios de comunicação social, teriam contribuído para que o tema ganhasse atenção global. Donaire (2010) afirma que há uma correlação positiva elevada entre o nível de conscientização de uma sociedade e os padrões de exigências e controles ambientais estabelecidos por ela para atividades industriais. Segundo o autor, quanto maior a pressão social que uma comunidade ou nação exerce sobre seus produtores, mais restrita é a legislação ambiental que se aplica às atividades de produção.

Frente a este contexto, empresas industriais têm passado a desenvolver estratégias organizacionais que aliam e alinham ações de responsabilidade social, desenvolvimento sustentável, consumo consciente e desempenho ambiental de produtos e serviços (SOUZA et al., 2010). Atividades industriais podem e devem ser gerenciadas para amenizar os impactos ambientais que ocasionam, o que inclui a variável ambiental na estratégia (SEHNEM et al., 2012). Uma empresa industrial pode incorporar a gestão ambiental na estratégia de operação pela identificação de ameaças, oportunidades, pontos fortes e pontos fracos da empresa, resultando planos que construam vantagem competitiva (DONAIRE, 2010). Neste sentido, Brock (2012) comprovou que pressões exercidas pela legislação vigente e por 
clientes, acionistas e financiadores de operações industriais podem induzir a empresa a introduzir práticas mais amigáveis ambientalmente na sua estratégia de operação. Por fim, Oliveira e Pinheiro (2009) afirmam que os Sistemas de Gestão Ambiental (SGAs) têm sido uma das alternativas mais utilizadas pelas empresas para alcançar objetivos estratégicos de integração de atividades de preservação e de construção de vantagem competitiva com base em gestão ambiental.

Portanto, é de interesse deste artigo revisar os SGA's.

\subsection{Sistemas de Gestão Ambiental}

Conforme Dias (2011), sistemas de gestão ambiental compreendem todas as atividades de gestão empresarial orientadas para identificar riscos e prevenir problemas ambientais. Pode-se dizer que esta é a parte da gestão empresarial que busca o desenvolvimento econômico da empresa em harmonia com o meio ambiente em que a empresa atua. Em síntese, a gestão ambiental atua para prevenir ou ao menos reduzir impactos negativos causados na natureza pela atividade industrial.

Um Sistema de Gestão Ambiental (SGA) é parte integrante da estratégia empresarial cujo objetivo principal é responder à demanda social por desenvolvimento ambientalmente correto. Um SGA pode ser definido como a parte do sistema de gestão de uma organização utilizada para desenvolver e implementar sua política ambiental e para gerenciar seus aspectos ambientais (Associação Brasileira de Normas Técnicas - ABNT, 2004). SGA's podem fazer parte de sistemas integrados de gestão (GRAEL; OLIVEIRA, 2010), incluindo gestão da qualidade, saúde e segurança do trabalho, responsabilidade social, gestão de riscos, entre outros (BRENDLER; BRANDLI, 2011). De forma geral, pode-se dizer que o objetivo principal de um SGA é melhorar simultaneamente o desempenho econômico e ambiental de uma atividade empresarial. Objetivos parciais de SGA são reduzir a exigência por recursos de produção, recursos energéticos e matérias-primas e ainda aumentar a produtividade das operações industriais. Ao menos, a contribuição de SGA's é manter lucrativas as atividades da empresa e sempre dentro da legalidade, evitando multas e ações judiciais relativas a mau desempenho ambiental (PEARSON, 2011). 
Em 1991, a International Organization for Standardization (ISO) criou um Grupo Assessor Estratégico sobre Meio Ambiente (Strategic Advisory Group on Environment - SAGE), para analisar a necessidade de desenvolvimento de normas internacionais na área do meio ambiente. Durante a Conferência das Nações Unidas sobre Meio Ambiente e Desenvolvimento, realizada no Rio de Janeiro em junho de 1992, o Conselho Empresarial para o Desenvolvimento Sustentável, presidido pelo empresário suíço Stephan Schmidheiny, apoiou a criação de um comitê específico, na ISO, para tratar das questões de gestão ambiental. Em março de 1993, a ISO estabeleceu o Comitê Técnico de Gestão Ambiental, ISO/TC207, para desenvolver uma série de normas internacionais de gestão ambiental, a exemplo do que já vinha sendo feito pelo ISO/TC 196, com a série ISO 9000 de Gestão de Qualidade. A série, que recebeu o nome de ISO 14000, refere-se a vários aspectos integrados e correlatos, tais como: sistemas de gestão ambiental, auditorias ambientais, rotulagem ambiental, avaliação do desempenho ambiental, avaliação do ciclo de vida e terminologia (NBR ISO, 2004).

Na série 14000, inclui-se a ISO 14001 que se refere especificamente a Sistemas de Gestão Ambiental e é a única da família que permite a certificação de um SGA. A certificação pode, além de melhorar o desempenho, construir uma imagem corporativa positiva da empresa perante o público, pois, quando uma empresa recebe uma certificação ambiental ela demonstra à sociedade que sua política ambiental é profícua e continuada (PEARSON, 2011). Implementar um SGA não é sinônimo de certificá-lo, uma vez que a certificação pode ser voluntária (BOIRAL; HENRY, 2012). Epelbaum (2006) salienta que uma organização pode se limitar a implementar o SGA, obtendo os benefícios específicos, e não solicitar credenciamento externo, advindo de empresas auditoras e devidamente credenciadas para emitir certificações aos SGAs que atendam efetivamente à Norma ISO 14001 (IRALDO et al., 2009).

As normas ISO 14001 formam um dos modelos de gestão ambiental que mais foram implantados por empresas industriais no mundo. Uma das característica destas normas é a padronização de rotinas e procedimentos de atuação ambiental. A norma não se contrapõe à legislação local, mas a fortalece, pois exige total 
cumprimento de todas as legislações vigentes para que ocorra a certificação (VALLE, 2002).

A norma ISO 14001:2004 é organizada em: introdução; objetivo; referências normativas; termos e definições; requisitos do sistema de gestão ambiental (requisitos gerais, política ambiental, planejamento, implantação e operação, verificação e ação corretiva, e análise crítica pela administração); e orientações para o uso da norma (OLIVEIRA e PINHEIRO, 2010). Talvez a maior contribuição que a norma ofereça é uma estrutura formal para o gerenciamento ambiental. O objetivo desta estrutura formal é oferecer um mecanismo para aumentar continuamente o desempenho ambiental de uma atividade empresarial (DONNELLY et al., 2004). Por fim, relacionando com o objetivo deste artigo, vale destacar que os princípios de uma das normas da família, a ISO 14031, têm subsidiado modelos que foram propostos na literatura para avaliação de desempenho ambiental baseado em indicadores ambientais (CAMPOS; MELO, 2008).

\subsection{Gestão Ambiental em PME}

Empresas de pequeno e médio porte (PME) são importante fator de desenvolvimento socioeconômico para o Brasil (HENNIG et al., 2012). Normalmente, PME's têm se preocupado mais com problemas que ameaçam sua sobrevivência, tais como: dificuldade de acesso ao crédito, juros mais elevados do que para grandes empresas e dificuldade de acesso a mercados mais competitivos. Diante desse cenário, para as PME's, questões relativas a desempenho e gestão ambiental, muitas vezes, tornam-se objetivos secundários que não interferem em sua sobrevivência imediata. Geralmente, os custos envolvidos em ações ambientais são considerados elevados e os retornos são calculados apenas do ponto de vista financeiro. Deste modo, as ações de correção e prevenção de danos ambientais resultam motivadas em grande parte pela pressão dos órgãos de controle e da legislação vigente, não por uma estratégia articulada e formulada pela empresa (NOGUEIRA et al., 2011).

No entanto, de acordo com Seiffert (2011), a implantação de um SGA por empresas de pequeno e médio porte (PME) pode possibilitar um aprimoramento no desempenho ambiental, não apenas associado ao cumprimento da legislação ambiental, mas também como uma forma de aumentar a competitividade em 
mercados globalizados. Alcançando excelência ambiental, a PME pode, em parceria com empresas maiores, acessar mercados mais promissores do que os locais (QUAZI; PADIBJO, 1998).

Seiffert (2011) aponta que o baixo nível de gerenciamento observado nas PME's e a baixa disponibilidade de capital e recursos humanos são motivos que dificultam a realocação de recursos necessários para implantação de princípios de gerenciamento ambiental. Os mesmos motivos dificultam iniciativas de certificação externa de um SGA neste tipo de empresa.

Diante deste cenário, observa-se que PME's podem e devem estruturar e organizar estratégias comuns que permitam responder às exigências da legislação ambiental vigente e também às demandas da sociedade consumidora por produtos e processos gerenciados de modo ambientalmente responsável. O estabelecimento de um sistema de gestão ambiental formal certificado pode não ser necessário, desde que os objetivos de gestão ambiental sejam claramente definidos e as ações articuladas com este objetivo (ALPERSTEDT et al., 2010).

A aplicação de um método de mensuração de desempenho ambiental como o que foi feito neste artigo pode ajudar PME's a avançar na direção de uma operação ambientalmente mais amigável, sem custos expressivos e sem necessidade de certificação externa de seu sistema de gestão.

\section{DESEMPENHO AMBIENTAL}

O desempenho ambiental de uma atividade empresarial pode ser definido como a informação analítica oferecida por um conjunto de indicadores que permite comparar entre si, ou contra uma referência externa, requisitos ambientais em setores de uma empresa, em atividades de uma cadeia produtiva, ou em empresas de uma mesma indústria ((BAULER, 2012; MAZZI et al., 2012; BOIRAL; HENRY, 2012). Para que o desempenho ambiental de uma atividade empresarial possa ser medido e acompanhado, são necessários indicadores de desempenho ambiental definidos e devidamente alinhados às estratégias, objetivos e metas da atividade (ASKHAM, 2012; CAMPOS; SELIG, 2002). Indicadores ambientais podem capturar dados complexos, originados de várias fontes e segundo vários modos de 
mensuração, e transformá-los em uma estrutura sintética e comunicável, tal como um índice global. Por meio de mensuração permanente e comunicação do desempenho ambiental se pode promover e disseminar políticas que previnam problemas, minimizem riscos de acidentes e construam uma imagem corporativa positiva para a empresa (ASKHAM et al., 2012; SELLITTO et al., 2008).

Conforme já mencionado, uma forma que a indústria usa para responder às pressões institucionais por melhor desempenho ambiental é implantando SGA's. Estes sistemas, entre outros requisitos, exigem modelos para a medição de desempenho ambiental, baseados em indicadores quantitativos. Indicadores quantitativos não expressam a realidade, mas são uma simplificação aceitável dela, que torna mais fácil e mais simples a comunicação de uma variável complexa, tal como é o desempenho ambiental (LUZ et al., 2006). Indicadores quantitativos são importante elemento de gestão estratégica observados em gestão verde de cadeias de suprimentos, a GSCM (SELLITTO et al., 2013). Dale e Gerlak (2007) alertam que pode haver no meio empresarial uma tendência de avaliar progressos ambientais somente por dados quantitativos, apesar da inerente complexidade presente na gestão de recursos naturais. Os autores enfatizam a necessidade de modelos elaborados para o uso de indicadores em medição de desempenho de programas ou estratégias ambientais, em complemento aos relatórios de gestão baseados em abordagens qualitativas.

Vários métodos foram propostos na literatura. Alguns foram revisados ou mencionados em Sellitto et al. (2012). Para este artigo, interessa o método SBP, aplicado em atividades industriais (SELLITTO et al., 2010).

\subsection{O método SBP}

O método SBP promove a avaliação do desempenho ambiental por meio da análise de indicadores que respondem a grandes áreas denominadas construtos. Seu objetivo é determinar e encerrar em um índice global o desempenho ambiental de uma operação industrial. Em linhas gerais, pode-se dizer que a mensuração do desempenho ambiental por este método se dá de maneira simples e não implica custos significativos para a medição, pois usa julgamento de especialistas e gestores, analisa informações disponíveis na empresa e pode se adaptar as mais 
diferentes atividades industriais. O resultado das avaliações parciais é representado em escalas de julgamento.

Mensuração por escalas de julgamento envolve alguma subjetividade, mas exige menos esforço e menos recursos do que exigiria uma mensuração mais objetiva, baseada em variáveis de campo. Essa característica do método permite que os cálculos envolvidos sejam mais simples do que os requeridos por modelos de medição baseados em instrumentação de campo. Portanto, não há necessidade de softwares específicos para tratamento de dados do tipo probabilístico ou instrumentação de campo, normalmente onerosos para o interesse de pequenas e médias empresas (ANTONOV; SELLITTO, 2011). O SBP é qualitativo e subjetivo e traz toda a riqueza das avaliações sintetizadas em uma informação final. $\mathrm{Na}$ subjetividade dos especialistas e da gestão estão incorporados os valores socioculturais, a visão político-econômica e o conhecimento físico-químico das circunstâncias em que a atividade industrial ocorre (KOHL; SELLITTO, 2009).

As características do método são: (i) o desempenho ambiental pode ser desdobrado em construtos latentes que descrevem como os processos ou atividades da organização estão relacionados ao impacto ambiental; (ii) os construtos podem ser apreendidos por indicadores; (ii) a prioridade dos construtos é indicada pela gestão; e (iii) o índice global oscila entre 0 e 100\%, o que facilita a comunicação dos resultados e a comparação entre operações.

A definição dos construtos e indicadores e a distribuição de importância relativa ocorrem em reuniões de grupo focado entre os gestores da empresa e o pesquisador. Cada participante do grupo manifesta sua opinião segundo a pontuação apresentada na Tabela 1. Faz-se a soma dos pontos de cada construto e a normalização. O vetor resultante dá as prioridades dos construtos. Opcionalmente pode-se proceder à avaliação de importância também dos indicadores que compõem cada um dos construtos, contudo nas pesquisas realizadas com o uso do método nota-se uma tendência em distribuir uniformemente as importâncias. No julgamento categórico, cada indicador é julgado pelos gestores ou especialistas nos processos por questionários e escalas, como na Tabela 2. A última etapa é a composição dos julgamentos, chegando a um valor final normalizado entre 0 e $100 \%$. 
Tabela 1- Distribuição de importância entre os construtos

\begin{tabular}{cc}
\hline Posição do Construto & Pontuação \\
\hline Mais Importante & 5 \\
Segundo mais Importante & 4 \\
Terceiro mais Importante & 3 \\
Quarto em Importância & 2 \\
Menos Importante & 1 \\
\hline
\end{tabular}

Fonte: Antonov e Sellitto (2011).

Tabela 2 - Desempenho dos indicadores

\begin{tabular}{cc}
\hline Julgamento & Nota \\
\hline Ótimo & 1 \\
Bom & 0,75 \\
Médio & 0,50 \\
Ruim & 0,25 \\
Péssimo & 0 \\
\hline
\end{tabular}

Fonte: Antonov e Sellitto (2011).

\section{A Pesquisa}

O objetivo deste artigo foi avaliar o desempenho ambiental de uma empresa anodizadora de superfícies de alumínio. A empresa é do tipo PME. O método de pesquisa foi a modelagem qualitativa numérica, materializada na aplicação do método SBP para avaliação do desempenho ambiental. O método de trabalho foi: (i) por entrevista com o gerente de operações industriais, foi entendida a realidade da empresa antes da aplicação; (ii) por grupo focado com dez gestores da empresa, foram priorizados os construtos (extraídos de pesquisas anteriores) e identificados os indicadores que podem explicar o desempenho ambiental da operação; (iii) os mesmos dez gestores avaliaram a situação dos indicadores para obtenção de um índice final de desempenho ambiental da operação; e (iv) pelas lacunas de desempenho apontadas pela avaliação, foram priorizados indicadores e construto para ações de correção.

A principal contribuição de pesquisa é mais um caso de aplicação do método SBP, desta vez em PME. O caso, em conjunto com os anteriores, pode contribuir para uma futura teoria fundamentada sobre desempenho ambiental em operações 
ambientais. As principais técnicas de pesquisa foram a entrevista semi-estruturada com o gerente industrial, o grupo focado e o questionário com os dez avaliadores.

\subsection{Caracterização da empresa: situação perante desafios ambientais}

A empresa estudada neste caso é de médio porte e atua no ramo de tratamento superficial de alumínio, operando um processo conhecido como anodização. A anodização é um processo eletrolítico ou eletroquímico que promove a formação de uma camada controlada e uniforme de óxido na superfície do alumínio, um método bastante aceito e bem definido para produzir uma película decorativa e protetiva de alta qualidade nas ligas de alumínio (ABAL - Associação Brasileira do Alumínio, 2005).

A anodizadora está no mercado há vinte anos, sendo que nos últimos cinco anos tem sofrido pressão por maior comprometimento com a questão ambiental. Esta pressão tem sido exercida pelos maiores clientes tomadores de serviços de anodização, dentre os quais figuram grandes empresas fabricantes de produtos a base de alumínio. Tal situação fez com que a anodizadora incorporasse a seus procedimentos de produção práticas de gestão de meio ambiente. A relação entre a anodizadora e seus clientes é similar ao que descrevem Quazi e Padibjo (1998). Os autores relatam que muitas vezes as pequenas e médias empresas são fornecedoras de serviços quase exclusivamente para grandes empresas. Dessa forma, ficam suscetíveis a sentir o impacto da imposição dos programas de qualidade e de gestão ambiental promovidos por estas grandes empresas.

A anodizadora não possui um SGA formal e nem certificações por normas da série ISO. Um objetivo de gestão da empresa é a consolidação e o aprofundamento de práticas ambientalmente corretas já em andamento na empresa. A incorporação de uma rotina de gestão ambiental nas práticas operacionais cotidianas tem se mostrado difícil. Várias ações conduzidas pela gerência e inicialmente bem sucedidas não foram consolidadas e incorporadas ao padrão operacional da empresa, por falta de conscientização do pessoal e falta de mecanismo gerencial formal de cobrança. Disseminar entre todos os setores e funcionários a importância e representatividade da questão ambiental para a organização é algo de grande importância, pois a eficácia e continuidade do sistema de gestão, assim como o 
melhor desempenho ambiental, estão associadas ao comprometimento de todas as pessoas da empresa para com os mesmos. Sobre esta questão, Callenbach et al. (1998) argumentam que enquanto os funcionários não estiverem convencidos, o projeto malogrará, não importa quão bem tenha sido elaborado sob outros aspectos. Pacheco et al (2009) apontam que é importante que os empregados tenham consciência das questões ambientais que a empresa enfrenta e de que forma suas ações influenciam no desempenho ambiental da mesma. Apontam também, que os gerentes e os empregados com responsabilidades ambientais devem possuir conhecimento técnico detalhado para assegurar o atendimento às normas e exigências comerciais e legais.

A conclusão é de que as práticas adotadas até o momento ainda não estão disseminadas na cultura da empresa. Tal fato revela a necessidade de reforço na estratégia de inclusão ambiental que tem sido proposta para a empresa. A realização deste objetivo é pretendida com a aplicação e comunicação dos resultados do método SBP.

\subsection{Resultados}

Os construtos utilizados foram extraídos da pesquisa realizada por Kohl e Sellitto (2009): atmosfera, efluentes, resíduos sólidos, recursos naturais e energéticos, e atendimento à legislação. Estes construtos têm sido repetidos em outras pesquisas da mesma linha (SELLITTO et al., 2012) e tem sido considerados suficientes pelos pesquisadores para capturar desempenhos ambientais em operações industriais. Os quatro primeiros construtos organizam os diversos tipos de ataques e de perdas ambientais que a atividade industrial pode gerar. $O$ quinto representa uma condição necessária e apriorística que pode facilitar o desempenho nos outros construtos, porém, considerada isoladamente, tem pouco valor: o objetivo da gestão ambiental não é apenas cumprir-se a lei, mas, ao cumprir a lei, pode-se prevenir perdas e ataques ambientais mensurados pelos construtos de campo.

Em sessões de grupo focado com dez avaliadores (diretores, gerentes, químicos e responsável técnico), todos conhecedores do processo, influentes na empresa e ligados à gestão ambiental, foram definidos os dezenove indicadores categóricos relacionados que representam a operação e os construtos e apreendem 
o conteúdo de um objeto complexo que pode ser chamado de desempenho ambiental. Observa-se que os avaliadores decidiram que a existência de sistema de gestão ambiental com certificação formal, tal como ocorre com as normas ISO 14.000, não eram necessários para a empresa. O sistema de gestão específico que foi montado pela empresa para atendimento das exigências legais foi considerado satisfatório pelos avaliadores e a implantação de um sistema com certificação formal traria sombreamento com funções hoje já desempenhadas pelo sistema e exigiria ações de monitoramento e gestão de menos eficácia, para que se obtivesse e mantivesse a certificação.

A Figura 1 relaciona os indicadores selecionados aos construtos de pesquisa.

Figura 1- Estrutura de Construtos e Indicadores

\begin{tabular}{|c|c|}
\hline Atmosfera & Efluentes \\
\hline $\begin{array}{l}\text {-Ruído } \\
\text { Extemo } \\
\text {-Poeira } \\
\text {-Odores } \\
\text { - Fumaça } \\
\text { veicular }\end{array}$ & $\begin{array}{l}\text {-Óleos } \\
\text { Lubrificantes } \\
\text {-Efluentes do } \\
\text { processo }\end{array}$ \\
\hline
\end{tabular}

\begin{tabular}{|l|}
\hline Resíduos \\
Sólidos \\
\hline -Lodo EIE \\
- Embalagens \\
de produtos \\
químicos \\
- Lâmpadas \\
-Papel, \\
Papeläo e \\
Plástico \\
\hline
\end{tabular}

\begin{tabular}{|l|}
\hline Recursos \\
Naturais e \\
Energéticos \\
\hline -Consumode \\
Água \\
-Consumode \\
Energia \\
Elética \\
-Consumode \\
fime plástico \\
-Consumode \\
Combustíveis \\
fósseis \\
-Consumode \\
Papel \\
\hline
\end{tabular}

\begin{tabular}{|l|}
\hline Legislação \\
\hline -Atendimento \\
à Legisłação \\
da Uniāo \\
-Atendimento \\
à Legislaçäo \\
Estadual \\
-Atendimento \\
à Legislação \\
Municipal \\
-Licença PF \\
\end{tabular}

Fonte: elaborada pelos autores

Com apoio de questionários objetivos, os dez avaliadores atribuíram importâncias aos construtos. Os critérios utilizados foram os mesmos da Tabela 1 e a pontuação atribuída pelos julgadores é apresentada na Tabela 3.

Tabela 3 - Pontuação atribuída pelos avaliadores

\begin{tabular}{|c|c|c|c|c|c|c|c|c|c|c|c|c|c|}
\hline \multirow[b]{2}{*}{ Construtos } & \multicolumn{10}{|c|}{ Avaliadores } & \multicolumn{3}{|c|}{ Resultados } \\
\hline & A & $\mathrm{B}$ & $\mathrm{C}$ & $\mathrm{D}$ & $E$ & $\mathrm{~F}$ & G & $\mathrm{H}$ & 1 & $\mathrm{~J}$ & Total & Prioridade & Ordem \\
\hline Atmosfera & 3 & 3 & 1 & 1 & 3 & 1 & 1 & 2 & 4 & 3 & 22 & $15 \%$ & $5^{\circ}$ \\
\hline Efluentes & 2 & 1 & 4 & 2 & 2 & 3 & 3 & 5 & 1 & 2 & 25 & $17 \%$ & $4^{\circ}$ \\
\hline $\begin{array}{l}\text { Resíduos Sólidos } \\
\text { Recursos Naturais e }\end{array}$ & 4 & 4 & 5 & 3 & 4 & 5 & 5 & 4 & 3 & 1 & 38 & $25 \%$ & $1^{\circ}$ \\
\hline Energéticos & 5 & 2 & 3 & 4 & 5 & 2 & 2 & 3 & 5 & 4 & 35 & $23 \%$ & $2^{\circ}$ \\
\hline Atendimento à Legislação & 1 & 5 & 2 & 5 & 1 & 4 & 4 & 1 & 2 & 5 & 30 & $20 \%$ & $3^{\circ}$ \\
\hline & & & & & & & & & Tot & tal & 150 & $100 \%$ & \\
\hline
\end{tabular}


A ordem dos vetores de prioridade evidencia a posição do construto em relação aos demais no que se refere à sua capacidade de influenciar o desempenho ambiental da operação. O vetor de prioridades é o resultado do cálculo da razão entre o somatório da importância atribuída ao construto e o somatório total. $\mathrm{O}$ vetor revela a distribuição das importâncias relativas entre os construtos.

O mesmo grupo julgou o desempenho dos indicadores, também com o auxílio de questionários objetivos e segundo o conteúdo da Tabela 2. A Tabela 4 apresenta a média da pontuação atribuída pelos respondentes ao desempenho de cada um dos indicadores, o coeficiente de variação $(c v)$, o desempenho de indicadores e construtos, a lacuna dos construtos e o índice global que é o resultado da avaliação de desempenho ambiental. Como o número de respondentes é grande, então se julgou contraproducente apontar todas as respostas individuais, aproveitando-se o espaço da tabela para agregar observações do grupo de avaliadores sobre os indicadores que foram estudados. 
Tabela 4 - Resultados

\begin{tabular}{|c|c|c|c|c|c|c|c|}
\hline \multirow[b]{2}{*}{ Construtos } & \multirow[b]{2}{*}{ Indicadores } & \multirow[b]{2}{*}{ Situação } & \multirow[b]{2}{*}{ média } & \multirow[b]{2}{*}{$\mathrm{CV}$} & \multicolumn{3}{|c|}{ Desempenho (pp) } \\
\hline & & & & & Indicador & Construto & Lacuna \\
\hline atmosfera & Ruído externo $3,75 \%$ & Não é feita medição & 0,55 & 0,19 & 2,06 & 9,47 & 5,53 \\
\hline \multirow[t]{3}{*}{$15 \%$} & Poeira $3,75 \%$ & É feita medição e controle & 0,73 & 0,11 & 2,72 & & \\
\hline & Odores $3,75 \%$ & É feita medição e controle & 0,65 & 0,2 & 2,44 & & \\
\hline & Fumaça veicular $3,75 \%$ & Não é feita medição & 0,6 & 0,21 & 2,25 & & \\
\hline efluentes & Óleos lubrificantes $8,5 \%$ & Tratados em ETE & 0,6 & 0,27 & 5,1 & 11,48 & 5,53 \\
\hline $17 \%$ & Efluentes do processo $8,5 \%$ & Enviado a aterro & 0,75 & 0,13 & 6,38 & & \\
\hline resíduos & Lodo gerado ETE $6,25 \%$ & Enviado à reciclagem & 0,83 & 0,15 & 5,16 & 21,09 & 3,91 \\
\hline \multirow[t]{3}{*}{ sólidos $25 \%$} & Lâmpadas $6,25 \%$ & Retorna ao fornecedor & 0,75 & 0,11 & 4,69 & & \\
\hline & Embalagem produto químico $6,25 \%$ & Retorna ao fornecedor & 0,9 & 0,14 & 5,63 & & \\
\hline & Papel, papelão e plástico $6,25 \%$ & Enviado à reciclagem & 0,9 & 0,14 & 5,63 & & \\
\hline recursos & Consumo de água $4,60 \%$ & média: $75 \mathrm{~m}^{3}$ mensais & 0,58 & 0,36 & 2,65 & 13 & 10 \\
\hline naturais e & Consumo de energia elétrica $4,60 \%$ & média: $3.460 \mathrm{kWh}$ mensais & 0,43 & 0,28 & 1,96 & & \\
\hline energéticos & Consumo de filme plástico $4,60 \%$ & não é controlado & 0,55 & 0,23 & 2,53 & & \\
\hline \multirow[t]{2}{*}{$23 \%$} & Consumo de combustível fóssil $4,60 \%$ & não é controlado & 0,58 & 0,23 & 2,65 & & \\
\hline & Consumo de papel $4,60 \%$ & Consumo controlado e variável & 0,7 & 0,18 & 3,22 & & \\
\hline legislação & Atendimento à Legislação federal $5 \%$ & Atende e possui licença & 0,98 & 0,08 & 4,88 & 19,5 & 0,5 \\
\hline \multirow[t]{4}{*}{$20 \%$} & Atendimento à Legislação estadual 5\% & Atende e possui licença & 0,98 & 0,08 & 4,88 & & \\
\hline & Atendimento à Legislação municipal $5 \%$ & Atende e possui licença & 0,98 & 0,08 & 4,88 & & \\
\hline & Licença Polícia Federal 5\% & Atende e possui licença & 0,98 & 0,08 & 4,88 & & \\
\hline & & & & & total & 74,5 & 25,5 \\
\hline
\end{tabular}

Fonte: Elaborada pelos autores 
As importâncias relativas dos construtos são dadas pelos vetores de prioridade da Tabela 3. Para os indicadores, foram utilizadas importâncias uniformes de acordo com o construto correlacionado. O cálculo para determinar a importância dos indicadores é dado pela divisão da importância relativa do construto pelo número de indicadores que nele estão incluídos. Já o desempenho dos indicadores resulta da ponderação da média obtida pela pontuação de desempenho pela importância relativa. O somatório dos índices de desempenho dos indicadores fornece o desempenho do respectivo construto. As lacunas mostram a diferença entre a importância e o desempenho, representando o que o construto deixou de contribuir no cômputo do desempenho geral da operação.

A Figura 2 apresenta os indicadores por ordem numérica crescente, ou seja, do indicador com o pior desempenho em pontuação para os indicadores com as melhores pontuações, sempre segundo os avaliadores.

Figura 2 - Indicadores por ordem de pontuação

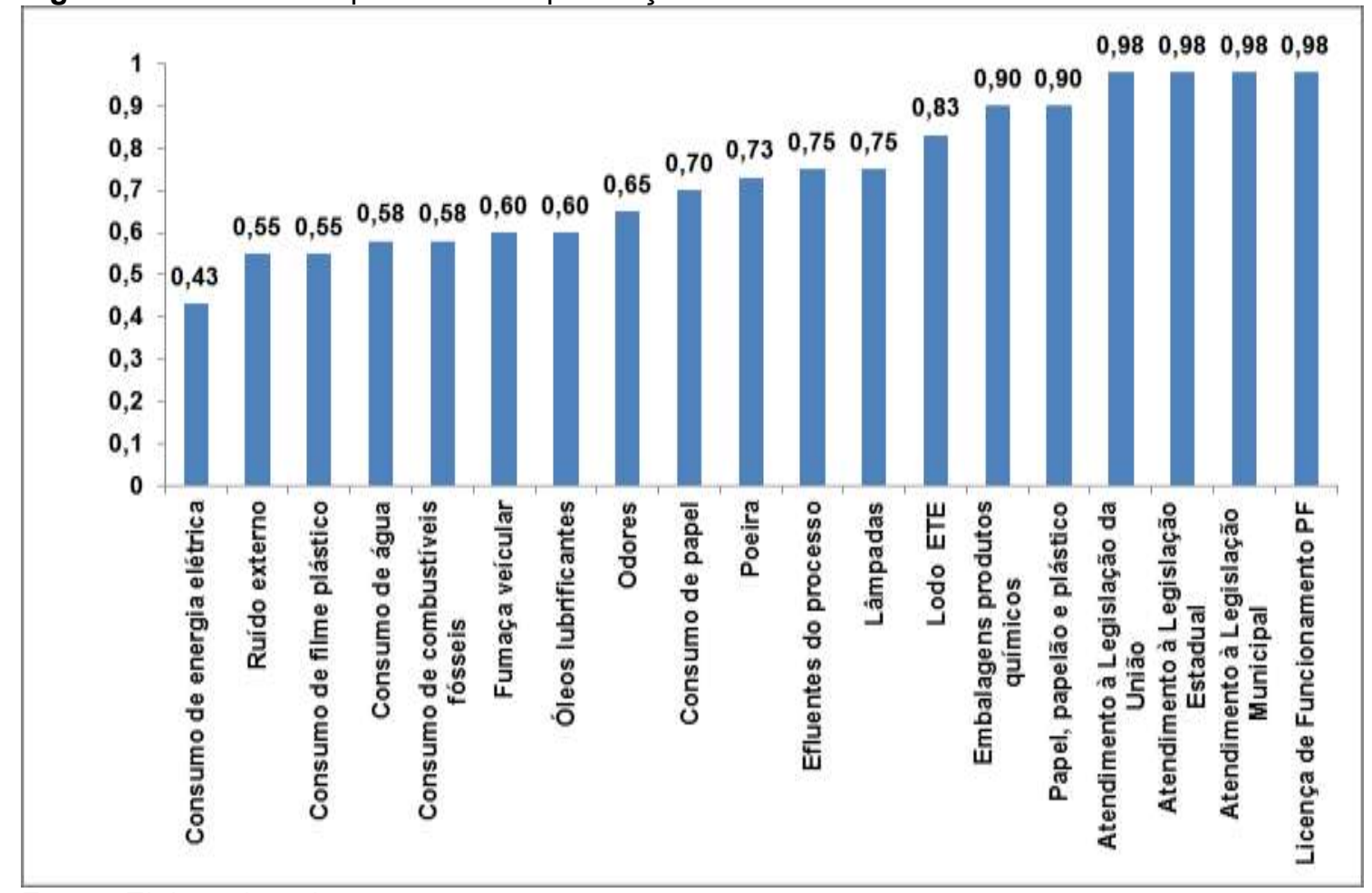

Fonte: Elaborada pelos autores

A pior avaliação foi conferida ao indicador para consumo de energia elétrica, com 0,43 pontos. Já os indicadores que fazem parte do construto 
legislação e gestão (atendimento à legislação da união, atendimento à legislação estadual, atendimento à legislação municipal e Licença da Polícia Federal) receberam as melhores avaliações, ficando com uma média de 0,98.

$O$ coeficiente de variação $c v$ é calculado pela razão entre o desvio padrão e a média dos valores referentes à avaliação de desempenho do construto. Elevados cv podem indicar dúvida razoável, o que gera disparidade de julgamento entre os respondentes. Essa disparidade pode estar ligada à falta de conhecimento sobre o fator em análise, ou pontos de vista discrepantes sobre o que seria um desempenho satisfatório. Neste caso, mesmo com média elevada, pode ser importante incluir os indicadores de alta variabilidade em eventual reformulação da estratégia ambiental (ANTONOV; SELLITTO, 2011).

A Figura 3 apresenta os coeficientes de variação em ordem crescente.

Figura 3 - Coeficientes de variação

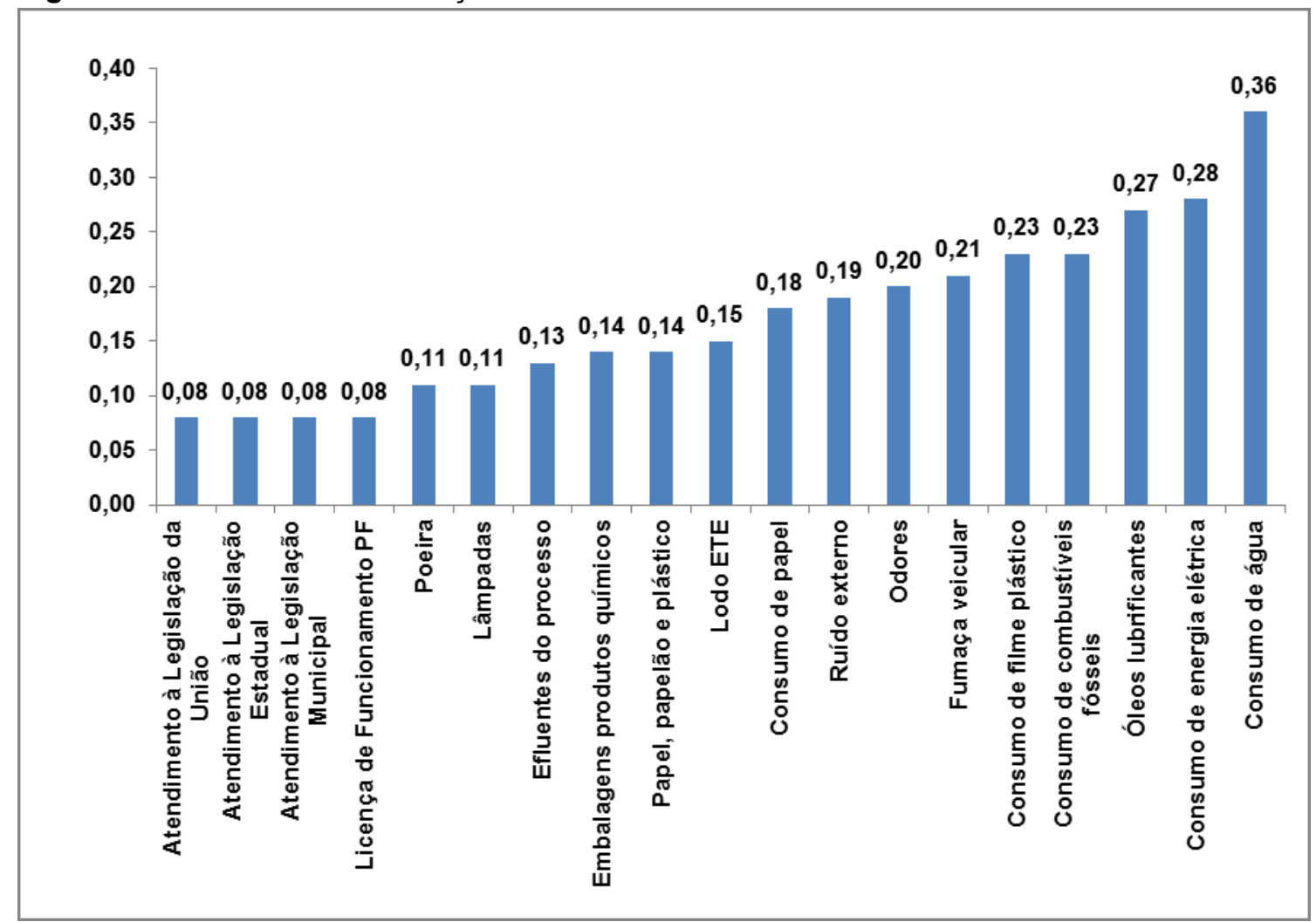

Fonte: elaborada pelos autores

Os maiores conflitos de opinião entre os avaliadores foram registrados nos indicadores consumo de energia elétrica e consumo de água. Estes indicadores também obtiveram pontuações baixas (Figura 2) e são os 
principais candidatos a serem objeto de planos de ação de correção, pois apresentam ao mesmo tempo baixo desempenho médio e alta variabilidade na avaliação. A priorização dos indicadores com pior resultado é importante para o caso da ação depender de recursos financeiros escassos. Recursos escassos podem e devem ser empregados prioritariamente nos indicadores em que seja maior a possibilidade de aumento no desempenho ambiental como um todo.

O índice de desempenho final obtido foi de $74,5 \%$. Apesar de ter sido confirmada a percepção relatada na revisão sobre atividades ambientais em PME, o valor calculado expressa um apreciável resultado para a empresa. A medição reforça a vontade gerencial de conduzir uma operação de manufatura amigável ambientalmente e demonstra a coerência das práticas que têm sido adotadas pela empresa com o objetivo estratégico de desenvolvimento da gestão ambiental. Contudo, as maiores lacunas, evidenciadas pelo estudo, alertam para os indicadores e construtos que necessitam de maior atenção da empresa para que o desempenho ambiental se aproxime de $100 \%$.

O pior desempenho entre os indicadores foi o de consumo de energia elétrica, que foi considerado alto pelos julgadores. Dentre os fatos levantados para explicar este resultado, podem-se citar a falta de manutenção nas instalações elétricas e em algumas máquinas, já obsoletas e que não receberam a manutenção adequada ao longo dos anos. Também se pode citar o sistema de climatização existente que, principalmente no verão, é fortemente requisitado devido à elevada temperatura que se observa nas instalações da manufatura. Como o mesmo é obsoleto, tem baixo rendimento e consome mais energia do que poderia. Também se pode citar que o consumo de energia elétrica pode ser reduzido se for completada a substituição de lâmpadas obsoletas por lâmpadas de baixo consumo de energia elétrica. A empresa já estudava, anteriormente ao resultado, adquirir uma máquina mais eficiente em produtividade e consumo de energia para a operação de polimento. Esta medida, frente à avaliação do indicador, pode reduzir o consumo e contribuir para um desempenho melhor em consumo de energia elétrica.

Outro indicador crítico é consumo de água $(0,58)$. A justificativa para esta baixa pontuação se dá pelo fato de o processo consumir grande quantidade de água, já que o alumínio necessita ser banhado em tanques que 
demandam bastante deste recurso. Além disso, não há um monitoramento rigoroso sobre a utilização da água nem um planejamento técnico que viabilize a maior eficiência na utilização da mesma. A água, uma vez utilizada, é destinada à Estação de Tratamento de Efluentes (ETE), pois o processo a contamina com produtos químicos. Após tratada, a água recircula no processo, mas não existem medições de perdas, que podem ser significativas.

Outro modo de priorizar ações é pelo desempenho de construtos. Em pesquisas anteriores (SELLITTO et al., 2010), observou-se que indicadores do mesmo construto podem estar correlacionados, ou seja, ações que interferem em um dos indicadores também interferem em outros, do mesmo construto. Por exemplo, no construto Atmosfera, ações que corrijam ruídos externos também podem corrigir poeiras e odores.

O pior desempenho entre os construtos foi o de Recursos Naturais e Energéticos. Sua importância relativa indicada pelos avaliadores ficou em 23\% e seu desempenho em 13 pontos percentuais. Além do indicador de consumo de energia elétrica e de água, já mencionados, fazem parte deste construto o consumo de filme plástico com $(0,55)$ e consumo de combustíveis fósseis $(0,58)$. Não há um programa gerencial de controle sobre estes insumos, o que torna sua situação crítica e justifica a má avaliação.

Passa-se então à análise dos melhores resultados.

O construto Legislação obteve a melhor avaliação em seus indicadores constituintes e a menor lacuna entre os construtos $(0,50)$. $O$ atendimento às legislações da união, estado e município mais a licença da polícia federal (requisito legal para compra e utilização de produtos químicos) obtiveram as médias mais elevadas $(0,98)$. Isto se deve à preocupação da empresa em atender aos órgãos competentes e responder às demandas legais exigidas.

Um indicador que vale a pena mencionar, relacionado à estação de tratamento, foi o relativo ao Lodo da ETE $(0,83)$, que faz parte do construto de Resíduos Sólidos. Na opinião dos avaliadores, o indicador foi julgado satisfatório. É importante que haja correta destinação deste resíduo, pois os danos ao meio ambiente podem ser sérios e de difícil reparo. A manufatura destina todo o lodo gerado a aterro sanitário, após passar por filtro que o separa da água. Após a secagem, o lodo é removido e encaminhado ao devido 
aterro sanitário por empresa credenciada para o transporte. Além disso, a empresa abriu as portas, recentemente, para pesquisadores interessados em coletar amostras e estudar a composição residual deste lodo, com o intuito de aplicá-lo na produção de um tipo de cimento e de cerâmicas, de acordo com a composição química que constatada. Caso esta iniciativa seja bem sucedida, poderá se tornar um caso de aplicação de logística reversa e poderá gerar dados para estudo de pesquisadores de vários campos de conhecimento.

\section{CONSIDERAÇÕES FINAIS}

O objetivo geral deste artigo foi avaliar o desempenho ambiental de uma empresa industrial que presta serviços de tratamento superficial de alumínio. A empresa é do tipo PME (pequena e média empresa). Os objetivos específicos do artigo foram: definir os construtos latentes e seus respectivos indicadores; mensurá-los; e usar a mensuração para discussão e priorização de ações ambientais. O método de pesquisa foi a modelagem numérica qualitativa.

Os elementos apresentados e os resultados obtidos permitem validar os objetivos de pesquisa. Com base em pesquisas anteriores, foram definidos cinco construtos latentes. Com base no grupo focado, conduzido pelos pesquisadores, foram definidos os indicadores. Os mesmos participantes do grupo focados avaliaram a situação dos indicadores. A mensuração foi usada para definir prioridades. As prioridades foram: indicadores de consumo de energia elétrica e de consumo de água e construto Recurso Naturais e Energéticos. Com estes elementos, entende-se que os objetivos secundários foram atingidos. Por decorrência, também foi atingido o objetivo principal.

O método auxiliou a empresa a analisar de modo organizado e estruturado e a baixo custo (não houve nenhuma despesa, apenas o tempo dos gestores dedicado ás atividades de pesquisa) o que está sendo promovido em termos de gestão ambiental. Outro reflexo foi a conscientização de que avaliar o desempenho ambiental deve ser um procedimento contínuo e permanente que pode e deve ser utilizado como ferramenta para apoiar a gestão para o meio ambiente na organização. Conclusivamente, pode ser dito, que para uma pequena ou média empresa, com características semelhantes à 
deste caso, o método pode funcionar como um direcionador de esforços de melhoria, e isto pode ser exatamente o que este tipo de empresa necessita para promover uma gestão com responsabilidade ambiental.

Como continuidade de pesquisa, sugere-se 0 uso de métodos multicritérios de apoio à decisão para a priorização dos construtos. Também sugere-se que seja flexibilizada a uniformidade de importância atribuída aos indicadores dentro dos construtos. Deste modo, os indicadores teriam importâncias diferenciadas entre si, contribuindo para uma maior especificidade na análise e definição das prioridades para as ações de melhoria.

\section{REFERÊNCIAS}

\section{ABAL - ASSOCIAÇÃO BRASILEIRA DO ALUMÍNIO. Guia técnico do} alumínio: Tratamento de Superfície. São Paulo: ABAL, 2005.

ASSOCIAÇÃO BRASILEIRA DE NORMAS TÉCNICAS. 1996a. NBR ISO 14001 - sistemas de gestão ambiental: especificação e diretrizes para uso. Rio de Janeiro: ABNT, 48 p.

ALPERSTEDT, G.; QUINTELLA, R.; SOUZA, L. Estratégias de gestão ambiental e seus fatores determinantes: uma análise institucional. RAE, v.50, n.2, p.170-186, 2010.

ANTONOV, P.; SELLITTO, M. Avaliação de desempenho ambiental: estudo de caso na indústria papeleira. Produção Online, v.11, n.4, p.1059-1085, 2011.

ARAUJO, P.; MACHADO, M. O novo estatuto do meio ambiente na prática empresarial mundializada: uma análise preliminar sobre a logística reversa. Gaia Scientia, v.1, n.1, p.67-75, 2007.

ASKHAM, C. REACH and LCA e methodological approaches and challenges. International Journal of Life Cycle Assess, v.17, n.1, p.43-57, 2012.

ASKHAM, C.; GADE, A.; HANSSEN, O. Combining REACH, environmental and economic performance indicators for strategic sustainable product development. Journal of Cleaner Production, v.35, n.1, p.71-78, 2012.

BAULER, T. An analytical framework to discuss the usability of (environmental) indicators for policy. Ecological indicators, v.17, n.1, p.38-45, 2012.

BOIRAL, O.; HENRI, J. Modelling the impact of ISO 14001 on environmental performance: a comparative approach. Journal of Environmental Management, v.99, n.1, p.84-97, 2012. 
BORCHARDT, M. et al. Considerações sobre ecodesign: um estudo de caso na indústria eletrônica automotiva. Ambiente \& Sociedade, v.11, n.2, p.341-353, 2008.

BRENDLER, E.; BRANDLI, L. Integração do sistema de gestão ambiental no sistema de gestão de qualidade em uma indústria de confecções. Gestão \& Produção, v.18, n.1, p.27-40, 2011.

BROCK, V. Gestão estratégica de operações sustentáveis: perspectiva institucional e abordagem dos stakeholders. Dissertação de mestrado em Administração. UNISINOS, São Leopoldo: 2012.

CALLENBACH, E.; CAPRA, F.; GOLDMAN, L.; LUTZ, R. Gerenciamento ecológico ecomanagement guia do instituto elmwood de auditoria ecológica e negócios sustentáveis. São Paulo: Cultrix, 1998. 203 p.

CAMPOS, L.; MELO, D. Indicadores de desempenho dos sistemas de gestão ambiental (sga): uma pesquisa teórica. Produção, v.18, n.3, p.540-555, 2008.

CAMPOS, L.; SELIG, P. SGADA - Sistema de gestão e avaliação do desempenho ambiental: a aplicação de um modelo de SGA que o utiliza o balanced scorecard (BSC). REAd, v.8, n.6, p.1-23, 2002.

CORAZZA, R. Gestão Ambiental e mudanças da estrutura organizacional. RAE eletrônica, v.2, n.2, 2003.

DELMAS, M.; BLASS, V. Measuring corporate environmental performance: the trade-offs of sustainability ratings. Business Strategy and the Environment, v.19, n.4, p.245-260, 2010.

DIAS, R.. Gestão ambiental responsabilidade social e sustentabilidade. São Paulo: Atlas, 2011. 220 p.

DINIZ, A.; OLIVEIRA, I. Influência das fontes de alumínio secundário na geração de escória: uma análise estatística. Produção Online, v.9, n.2, p.284302, 2009.

DONAIRE, D. Gestão ambiental na empresa. São Paulo: Atlas, 2010.

DONNELLY, K.; OLDS, R.; BLECHINGER, F.; REYNOLDS, D.; BECKETTFURNELL, Z. ISO 14001 - effective management of sustainable design. The Journal of Sustainable Product Design, v.4, n.2, p.43-54, 2004

EPELBAUM, M. A Influência da gestão ambiental na competitividade e no sucesso empresarial. São Paulo, SP. Dissertação (Mestrado)- Universidade de São Paulo, 2004. 167 p. 
GRAEL, P.; OLIVEIRA, O. Sistemas certificáveis de gestão ambiental e da qualidade: práticas para integração em empresas do setor moveleiro.

Produção, v.20, n.1, p.30-41, 2010.

HENNIG, E.; DANILEVICZ, A.; DUTRA, C. Modelo adaptado de planejamento estratégico aplicado à microempresas: um estudo de caso na área de fitness. Produção Online, v.12, n.2, p.270-296, 2012.

INTERNATIONAL ORGANIZATION FOR STANDARIZATION - Normas ISO 14001: gestão ambiental. Disponível em: <http://www.iso.org>. Acesso em: abr. de 2012.

IRALDO, F.; TESTA, F.; FREY, M. Is an environmental management system able to influence environmental and competitive performance? the case of the eco-management and audit scheme (emas) in the european union. Journal of Cleaner Production, v.17, n.16, p.1444-1452, 2009.

JABBOUR, C.; SANTOS, F. Evolução da gestão ambiental na empresa: uma taxonomia integrada à gestão da produção e de recursos humanos. Gestão \& Produção, v.13, n.3, p.435-448, 2006.

JURY, C. et al. Analysis of complementary methodologies to assess the environmental impact of Luxembourg's net consumption. Environmental Science \& Policy, v.27, n.1, p.68-80, 2013.

KOHL, C.; SELLITTO, M. Avaliação do desempenho ambiental de um operador de serviços logísticos por indicadores categóricos. Estudos Tecnológicos, v.5, n.3, p.284-301, 2009.

KUHRE, W. ISO 14031: environmental performance evaluation (EPE): practical tools techniques for conducting an environmental performance evaluation. Upper Saddle River: Prentice Hall, 1998.

LUZ, S.; SELLITTO, M.; GOMES, L. 2006. Medição de desempenho ambiental baseada em método multicriterial de apoio à decisão: estudo de caso na indústria automotiva. Gestão \& Produção, v.13, n.3, p.557-570, 2006.

MAZZI, A. et al. A. Is it possible to compare environmental performance indicators reported by public administrations? Results from an Italian survey. Ecological Indicators, v.23, n.6, p.653-659, 2012.

NOGUEIRA, A.; PERES, A.; CARVALHO, E. Avaliação do risco ambiental utilizando FMEA em um laticínio na região de Lavras - MG. Produção Online, v.11, n.1, p.194-209, 2011.

OLIVEIRA, O.; PINHEIRO, C. Implantação de sistemas de gestão ambiental ISO 14001: uma contribuição da área de gestão de pessoas. Gestão \&

Produção, v.17, n.1, p.51-61, 2010. 
PACHECO, N.; SILVEIRA, R.; CELESTINO, J. A importância de um sistema de gestão ambiental para empresa: o caso de uma construtora de grande porte. In: ENCONTRO NACIONAL DE ENGENHARIA DE PRODUÇÃO, 29,. 2009. Salvador. Anais... Salvador, 2009.

PEARSON, A. In: CURI, D. (Org.). Gestão ambiental. São Paulo: Person Education do Brasil, 2011. 312 p.

QUAZI, H.; PADIBJO, S. A journey toward total quality management through ISO 9000 certification - a study on small- and medium-sized enterprises in Singapore. International Journal of Quality \& Reliability Management, v.15, n.5, p.489-508, 1998

RIBEIRO, D.; MORELLI, M. Resíduos sólidos: problema ou oportunidade?. Rio de Janeiro: Interciência, 2009.

SANCHES, C. Gestão ambiental proativa. RAE - Revista de Administração de Empresas, v.40, n.1, p.76-87, 2000.

SEIFFERT, M. 2011. ISO 14001 Sistemas de gestão ambiental: implantação objetiva e econômica. 4. ed. São Paulo: Atlas, 239 p.

SELLITTO, M.; BORCHARDT, M.; PEREIRA, G. Avaliação de desempenho ambiental em duas operações de fabricação de grande porte. In: ENCONTRO NACIONAL DE ENGENHARIA DE PRODUÇÃO, 29,. 2009, Salvador. Anais... Salvador: ABEPRO, 2009a.

SELLITTO, M.; BORCHARDT, M.; PEREIRA, G. Avaliação de desempenho ambiental em duas operações de fabricação de pequeno porte. SIMPEP, 16,. 2009. Bauru, SP. Anais... Bauru: UNESP, $2009 \mathrm{~b}$.

SELLITTO, M.; BORCHARDT, M.; PEREIRA, G. Avaliação de desempenho ambiental em duas operações de manufatura. In: ENCONTRO NACIONAL DE ENGENHARIA DE PRODUÇÃO, 28o, 2008, Rio de Janeiro. Anais... Rio de Janeiro: ABEPRO, 2008.

SELLITTO, M.; BORCHARDT, M.; PEREIRA, G. Modelagem para avaliação de desempenho ambiental em operações de manufatura. Gestão \& Produção, v.17, n.1, p.95-109, 2010.

SELLITTO, M. et al. Environmental performance assessment of a provider of logistical services in an industrial supply chain. Theoretical Foundations of Chemical Engineering, v.46, n.6, p.691-703, 2012.

SELLITTO, M. et al. Gestão de cadeias de suprimentos verdes: quadro de trabalho e direção para futura pesquisa. Produção Online, v.13, n.1, p.351374, 2013. 
SEHNEM, S. et al. A. Gestão e estratégia ambiental: um estudo bibliométrico sobre o interesse do tema nos periódicos acadêmicos brasileiros. REAd Revista Eletrônica de Administração, v.18, n.2, p. 468-493, 2012.

SOUZA, M.; RÁSIA, K.; JACQUES, F. Evidenciação de informações ambientais pelas empresas integrantes do índice de sustentabilidade empresarial - ISE. Controle e Controladoria, v.2, n.1, p.51-139, 2010.

VALLE, C. Qualidade ambiental: ISO 14000. São Paulo: SENAC, 2002.

VILELA JÚNIOR, A.; DEMAJOROVIC, J. Modelos e ferramentas de gestão ambiental desafios e perspectivas para as organizações. São Paulo: Senac, 2010.

WALKER, H.; DI SISTO, L.; MCBAIN, D. Drivers and barriers to environmental supply chain management practices: lessons from the public and private sectors. Journal of Purchasing and Supply Management, v.14, n.1, p.69-85, 2008 .

ZOBEL, T.; ALMROTH, C.; BRESKY, J.; BURMAN, J. Identification and assessment of environmental aspects in an EMS context: an approach to a new reproducible method based on LCA methodology. Journal of Cleaner Production, v.10, n.4, p.381-396, 2002.

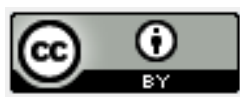

Artigo recebido em 26/06/2012 e aceito para publicação em 26/04/2013. 